\title{
Contrast of Electron Microscopy Images of Amorphous Objects
}

\author{
O.Ya. Svatiuk* \\ Uzhgorod National Universiry, 46, Pidhirna St., 88000 Uzhgorod, Ukraine
}

(Received 17 November 2015; published online 15 March 2016)

\begin{abstract}
It has been proposed to determine the contrast in electron microscopy image via the total electron fluxes scattered beyond the aperture diaphragm by local areas of the object under study to analyze quantitatively the amplitude (absorption) contrast of the amorphous objects with different types of heterogeneities of the atomic and continual structure. The significant properties of the determined contrast are its linear dependence on the difference of electron beam fluxes that form the image and a convenient range of variation from 0 to 1 relative units.
\end{abstract}

Keywords: Electron microscopy, Electron diffraction, Amplitude contrast, Amorphous material, Microstructure.

PACS numbers: 61.05.J -, 61.05.jd, 68.37.Lp

\section{INTRODUCTION}

Modern electron microscopy is a specific field of complex scientific and applied studies [1]. It is based on the physical phenomena that occur at the interaction with material of electron beam with the energy from dozens of thousands to some million electron-volts. As a result of such interaction, a set of different types of emission is produced carrying a large amount of information on the structure of the material under study. The transmission electron microscopy is an especially important direction of the structural studies of modern optoelectronics materials. Its main specific feature is obtaining the direct information on the structure of the whole volume of the sample under study both on the atomic and microstructural continual level.

Contrast formation in the transmission electron microscopy depends greatly on the mode of operation. The most common mode of operation in the transmission electron microscopy is the bright field imaging mode. Below we will consider this subfield of electron microscopy (EM) studies only. The results of such EM experiments are fixed in a form of the two principal complementary information sources: electron diffraction patterns (i.e. electronograms, diffractograms, microelectronograms, nanoelectronograms) and the EM images of different areas of the specimen under study. In this case the electron diffraction patterns carry information about the sample in a form convenient for studying its general atomic structure. As regards the EM images, in the most cases (except for the high resolution methods) they provide information about the specimen structure on the continual level.

The differences between different areas of the EM image are called the contrast. Analysis of the microstructure in the EM studies is reduced just to the comprehensive interpretation of the contrast patterns observed in the EM images reflecting specific features of the structure of the sample under study. Therefore, exactly the theory of the EM image contrasts is a fundamental problem of transmission electron microscopy [2].

Resolution in electron images is also normally limited by contrast, but not by lack of resolving power. Whereas the resolving power of the microscope is of the order $0.2-0.3 \mathrm{~nm}$, for most amorphous and biological specimens, resolution is limited to about $1-5 \mathrm{~nm}$. Contrast of images is determined by the nature and extent of interactions between the electron beam and the material. Properties of both the specimen (inherent contrast) and of the microscope system (instrumental contrast) are of importance here.

The contrast in the electron image can arise from both "amplitude" and "phase" effects. The amplitude contrast is produced by the difference between electron intensities of the portions of the beam that contribute to the image. The phase contrast originates from the shifts in the relative phases of the above portions. In general, amplitude contrast is dominant for structures with large mass thickness, while phase contrast increases in importance for small and thin structures and becomes the dominant source of contrast for very small objects of low atomic number. Unfortunately, the terms "amplitude" and "phase" contrast can be somewhat misleading, especially to those, who are familiar with similar terms used in crystallography. More appropriate terms are the "scattering" contrast and the "interference" contrast instead of the "amplitude" and "phase" contrast. However, to be consistent with the most texts and articles dealing with electron microscopy, in this paper the terms "amplitude" and "phase" contrast will be used.

The theory and the methods of interpreting contrast in the EM images of crystalline or partially crystalline substances are given in detail in many articles and monographs [1-4]. The number of works devoted to the detailed analysis of contrast formation in the EM images of amorphous materials is much less [5]. It is generally accepted that formation of the EM images of the amorphous objects could be described rather strictly within the framework of the amplitude contrast theory [6]. In the bright field imaging mode the contrast formation, when considered classically, is formed directly by occlusion and absorption of electrons in the sample.

The amplitude contrast theory is particularly

\footnotetext{
*alsv82@gmail.com
} 
developed for organic objects and materials comprising light atoms (C, $\mathrm{SiO}_{2}$ etc.) [7]. As a rule, it is assumed here that the microstructure of the material is highly homogeneous, while contrast heterogeneities in the EM images are primarily determined by the difference in thicknesses or masses of different local areas of the sample under study [2]. Just such objects are analyzed in the most experimental works on processing the EM images of the amorphous materials. In the experimental studies, such contrasts in the EM images are called the "mass-thickness" contrast and describe them mainly qualitatively, i.e. determine image homogeneity or heterogeneity, provide qualitative and several quantitative geometric parameters of heterogeneities.

Many amorphous objects reveal more complex structure on the microstructural level. Their EM images visualize the labyrinth, point and tweed contrasts [8], which are related to the phase layering in the homogeneous material. Globular columnar and cellular (granular, pillar-like) structures of amorphous samples are also met quite often $[9,10]$.

In the case of the amorphous materials with complex chemical composition, the different-type microstructure heterogeneity spectrum becomes much wider [11]. Therefore, existing theoretical approaches to analyzing the amplitude contrast of such objects are very limited and do not take into account a number of important factors that influence essentially the process of formation of their EM images. Accordingly, theoretical clarification of the character of the influence of different structural details of the complex amorphous samples on the quantitative parameters of their image contrast is an important and topical task. First, it is necessary to define unambiguously the physical principles of formation of the amplitude contrast in the EM images of the above objects, and this was the goal of the present paper.

\section{O MODEL OF FORMING THE AMPLITUDE CONTRAST OF THE EM IMAGES}

We shall assume that in the transmission electron microscopy the sample under study is ideally homogeneous if any allocated area of it has the same chemical and phase composition, atomic structure, spatial orientation with respect to the probing beam and all the parameters of the continual structure (density, thickness etc.) over the entire volume. Let the minimal size of the local area be determined by the microscope resolution. In the modern transmission electron microscopy, it could be about $1 \mathrm{~nm}$ in the plane of the object under study. At the $10 \mathrm{~nm}$ sample thickness such local area will include about one thousand of atoms and may be considered the microscopic continual system.

To obtain the EM image, a uniform probing electron beam is directed onto the sample under study (Fig. 1). In the transmission electron microscopy, electrons of two beams mainly take part in forming the diffraction pattern and the EM image of each local area of the sample: i) the central beam that comprises electrons from probing beam that have passed the sample with no changes and ii) the scattered electrons, i.e. those from the probing beam that have passed the local area and reflected to any extent from the central beam direction. In both cases, information about the local area structure is carried by electrons that have fully passed the above area (i.e. its full thickness). Just these two electron beams form the relevant EM image of a certain local area of the objects under study.

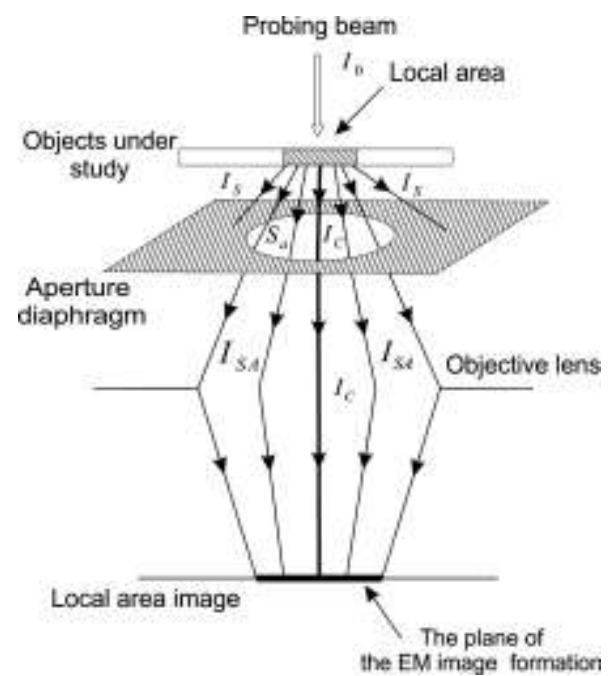

Fig. 1-Schematic layout of a certain local area image formation in the electron microscope

Obviously, after passing the ideally homogeneous sample by the microscope probing beam, the intensities of the central beam and scattered electrons will be the same for any local area. Respectively, the EM image of such sample formed by the above beams will be fully homogeneous as well.

Given the presence of local areas in the sample that differ by at least one of the above parameters, the central and the scattered electron beams will have different intensities for these areas. Such differences will be reflected in the EM image heterogeneities for this sample. Such image heterogeneities will definitely reproduce variations of parameters of atomic structure and continual structure of the object at the transition from one local area under study to another one.

Depending on the fact, which of the above two beams participates dominantly in the EM image formation and how do their intensities correlate, one may distinguish in the transmission electron microscopy the four principal types of contrast: the shadow, the diffraction, the amplitude (absorption) and the phase ones [12].

The simplest of them is the shadow contrast specified by the differences in the effective thicknesses (i.e. the density-thickness product) of different local area of the object under study. In its "pure" form, this contrast is formed dominantly by the central beams and is revealed in the objects with local areas differing greatly by their geometric thickness. The EM images of such objects have a light background representing thin areas and visualized thick areas in a form of a "geometric shadow". The shadow contrast is manifested mainly at large sizes of local areas in a form of an image with low resolution in the range of relatively low microscope magnifications (not higher than $10^{4}$ ).

Another type of the image contrast is the diffraction 
one and it is due to the coherently scattered electrons that interfere and produce the corresponding diffraction pattern. Since the electron beams being diffracted by various structural elements of the object under study are deflected by different angles, they will be differently held by the aperture diaphragm. The relevant local areas of the EM image of such objects that correspond to different structural elements will have different intensity. This type of contrast is formed simultaneously by the central and scattered beams and plays a principal role in the formation of the crystal object image with the average and low resolution within the microscope magnification range of $10^{4}$ to $10^{5}$.

The main type of the contrast in the EM images of different objects is the amplitude or absorption one. This contrast is revealed in the images of the thin object microstructure that contain different continual areas with linear dimensions exceeding much the interatomic distances. At the amplitude contrast the image is formed by the central electron beam having passed the sample without scattering and the part of electron beam that was scattered according to all mechanisms and passed the aperture diaphragm. The amplitude contrast differs from the diffraction one by that the amplitude and the phase of a part of scattered electron waves that form the amplitude contrast are not conserved, i.e. such contrast is formed by the scattered electrons both coherently and non-coherently. It is just the amplitude contrast that predominates in the EM images of the amorphous objects.

To form the phase contrast some scattered and central electron beams are chosen with electron waves that after passing the sample conserved both their phase and amplitude. When these beams join at the image plane, the EM images are produced with high resolution within the high magnification range (up to $\sim 10^{6}$ times). The phase contrast is formed predominantly for quite thin areas of the sample with the $d \leq 10 \mathrm{~nm}$ thickness and allows the image of crystallographic planes of the crystals and "images" of the separate atoms to be visualized.

Let us analyze the relation of intensities of the main electron beams that take part in forming the amplitude contrast of the EM images (Fig. 1). The probing beam of the electron microscope with the intensity $I_{0}$ is directed onto the object under study. The main part of the probing beam passes through the selected local area of the object without changes forming, thus, the central beam with intensity $I_{c}$. A part of electrons are scattered due to different mechanisms by this local area in all directions from the central beam forming a certain spatial distribution of intensity of scattered electron waves $I_{s}$. A small part of electrons are also absorbed in this area due to different processes. However, in the transmission electron microscopy, the conditions of studies are chosen in such a way that the absorption intensity is quite small as compared to the $I_{c}$ and $I_{s}$ values. One may assume here that electron absorption by the local area results in the central beam intensity $I_{c}$ variation, however, the values of such variation are several orders of magnitude less than the intensity $I_{c}$ itself, therefore further we will neglect electron absorption in the sample. In addition, to ensure exact quantitative analysis of the contrast in electron microscopy, the condition $I_{c} \gg I_{s}$ must hold true and this is valid for in the most of practical cases.

\section{DEFINITIONS AND PRINCIPLES OF DETERMINING THE AMPLITUDE EM CONTRAST OF THE AMORPHOUS OBJECTS}

In accordance with the model developed, in the light field mode, the EM image of the local area of the object is predominantly formed by the high-intensity central beam that passed this area and was fully transmitted by the aperture diaphragm (Fig. 1). At the same time a certain part of electrons of the probing beam scattered by the local area at small angles within the aperture diaphragm also pass this diaphragm. Let us denote Isa the spatial distribution of intensity of scattered electrons within the aperture diaphragm. Then the aperture diaphragm will trap a part of scattered electrons with the spatial intensity distribution $I_{a}=I_{s}-I_{s a}$.

The objective lens of the electron microscope in the certain plane forms from the beams Ic and Isa the image of the selected local area of the object (Fig. 1). Different local areas of the heterogeneous sample under study differ from each other by the electron scattering ability and by the degree of electron absorption. Therefore, each area will give its own contribution to the scattered emission distribution both within the aperture diaphragm $\left(I_{s a}\right)$ and beyond it $\left(I_{a}\right)$. The last quantity can be formally considered the characteristics of the intensity of electrons absorbed by a certain local area of the sample, since this emission is removed by the aperture diaphragm from the process of forming the image of this area. Correspondingly, the larger are the values Ia for a certain local area of the sample, the darker will be the area of the EM image that corresponds to the above local area. Thus, the value of the contrast between the two selected areas of the EM image will be expressly determined by the differences of the spatial distribution of intensities $I_{s}$ that are formed by the relevant local areas of the sample under study and are removed from the probing beam intensity $I_{0}$ influencing, thus, distributions of intensities $I_{c}$ and $I_{s a}$.

To perform the quantitative analysis of the EM images of the amorphous materials one has to formulate clear physical definition of the value of the amplitude (absorption) contrast between different local areas of the image and find simple and reliable methods of contrast calculation.

Various researchers suggest different definitions of the contrast in the EM image of objects. In particular, in [12], the contrast is treated as the natural logarithm of the ratio of intensity $I_{s a}$ of the beam that passed the local area of the object and was scattered within the aperture angle of the objective to that of the probing electron beam $I_{0}$, i.e.:

$$
K=\left|(1 / \gamma) \ln \left(I_{s a} / I_{0}\right)\right| .
$$

where $\gamma$ is the parameter that takes into account the specific features of the medium that registers the electron beam. Such definition has two significant shortcomings. First, the contrast here is introduced as the characteristic of the "intensity" of the image of each 
local area. In practice, more important and expedient is the contrast definition using the differences between the "intensities" of the images of two adjacent local areas of the object that corresponds exactly to the physical sense of the term "contrast". Second, the quantitative values of the contrast (1) will be expressed in the logarithmic scale within the range from zero to infinity at the transition from completely "transparent" to completely "dark" local areas of the object. Such logarithmic dependence between the contrast and intensity of electron beams that form the image of the local areas of the object is not practical and physically not understandable.

It follows from the above example that in the electron microscopy another, more physically clear, approach should be used to define contrast. In particular, in optics, by this quantity is meant the largest difference in luminosity of different object areas:

$$
K=\left(B_{\max }-B_{\min }\right) /\left(B_{\max }+B_{\min }\right)
$$

where $B_{\max }$ and $B_{\min }$ are the maximal and the minimal luminosities, respectively [13]. The photographic contrast definition is also close to relation (2), but here by the variable $B$ is meant the optical density of the photographic image darkening [14]. In electron microscopy, the closest to such physically strict definition of the EM image contrast shall be its setting in a form of variations of electron flux passing the aperture diaphragm from different local areas of the object. These variations appear due to that of the spatial distribution of electron beam intensities $I_{t}=I_{c}+I_{s a}$ at the transition from one local area to another one.

Thus, electron fluxes that form the EM contrast are described by the character of the spatial distribution of intensity $I_{t}$, which is a complex function of the three space coordinates. This function will be different for different local areas of the sample. In this case it seems hardly probable that for two selected local areas their intensity functions $I_{t 1}$ and $I_{t 2}$ will satisfy the condition $I_{t 2}=\alpha I_{t 1}$ in the entire spatial area of the aperture diaphragm. Therefore, when defining the amplitude EM contrast, more reasonable is considering the value of the total electron flux $\Phi_{t}$ that was formed at the probing beam interaction with the local area of the sample and passed the aperture diaphragm. Obviously, this flux is formed due to the spatial distribution of intensity $I_{t}$.

Further we will choose a separate local area of the sample in such a way that it will have the similar chemical and phase composition, atomic structure and spatial orientation with respect the probing beam, density, thickness and any other structural parameter over the entire volume. In this case the spatial distribution of intensity It in the region of the aperture diaphragm will be defined by a certain constant function for this local area. Integration of this function over the aperture diaphragm area will give the value of electron flux $\Phi_{t}$ that forms the image of the local area (Fig. 1). Since for all local areas of the sample the EM image is formed with the participation of the same aperture diaphragm of fixed size, the differences in the fluxes $\Phi_{t}$ originating from different local areas will be expressly defined by those in the spatial distributions of the intensities $I_{t}$ of these areas.

In our opinion, just the physical quantity $\Phi_{t}$ must make a ground for determining the EM image contrast. The use of this approach when taking into account (2) may be mathematically expressed by different relations, but the basis of all of them will be the following parameter $[2,5]$

$$
\Delta=\left|\Phi_{t 2}-\Phi_{t 1}\right| \text {. }
$$

where $\Phi_{t 1}$ and $\Phi_{t 2}$ are the electron wave fluxes It from the two different local areas of the object in the plane of formation of the EM image.

Thus, the amplitude contrast between the EM images of the two local areas of a given object is unambiguously determined by the ratio of the fluxes $\Phi_{t 1}$ and $\Phi_{t 2}$ of electron beams that interacted with the above areas and passed the aperture diaphragm of the microscope. To determine these values one has to measure experimentally the intensities of the central beams $I_{c 1}$ an $I_{c 2}$ and find the spatial distributions of the intensities $I_{s a 1}$ and $I_{s a 2}$ of the beams scattered within the aperture diaphragm for the two local areas. As of today, the spatial functions $I_{s a}$ and $I_{s}$ are determined quite accurately by means of the nano- and microdiffraction from the separate local areas of the object with the sizes starting from a few nanometers [16]. As regards the accurate measurements of the Ic values from different local nanosized areas in a standard electron microscope operating mode, they are related to certain difficulties, which, in fact, could be overcome in the practical microscopy.

Let us use one more condition fulfilled in the EM studies, i.e. the constancy of the intensity $I_{0}$ of the probing beam that falls onto the different local areas of the object. Then, within the framework of electron absorption smallness approximation, one may write for the selected local area of the sample:

$$
I_{0} \approx I_{c}+I_{s}=I_{c}+I_{s a}+I_{s \infty}=I_{t}+I_{s \infty},
$$

where $I_{s \infty}$ is the spatial intensity distribution function for the flux of electrons scattered beyond the aperture diaphragm. As follows from the above relation, the intensity distribution $I_{t}$, and, correspondingly, the flux value $\Phi_{t}$ from the local area of the sample are expressly determined by the difference $I_{t}=I_{0}-I_{s \infty}$ as well.

Thus, the fluxes $\Phi_{t}$ from different local areas of the sample could be also determined through the spatial intensity distribution function for the flux of electrons scattered beyond the aperture diaphragm $I_{s \infty}$. To do this, in the experimental studies it is convenient to take for analysis the local areas of the same areas in the sample plane. Then the electron flux of the probing beam in any area will be constant and equal to $\Phi_{0}$. If now we denote by $\Phi_{i}$ the total flux of the electron waves scattered beyond the aperture diaphragm from different local areas, then expression (3) will take a form:

$$
\Delta=\left|\Phi_{0}-\Phi_{2}-\Phi_{0}+\Phi_{1}\right|=\left|\Phi_{1}-\Phi_{2}\right| .
$$

Let us analyze in more detail the value $\Delta$ in the EM 
studies. Let us present it in a form of a mathematical expression with no modulus, having set that always $\Phi_{1} \geq \Phi_{2}$, i.e. the first area of the image is chosen darker. Then simply $\Delta=\Phi_{1}-\Phi_{2}$. In the practical electron microscopy, the values of the fluxes $\Phi$ may vary within a wide range. Its lower limit equals to zero for the local areas that completely transmit the probing electron beam with no scattering (the case of the local "hole" in the sample). The upper limit is equal to a certain maximal value $\Phi_{\max }$ for the local areas of the sample that are still applicable for the quantitative EM studies but produce an intense boundary scattering beyond the aperture diaphragm. Taking these conditions into account, one may write:

$$
0 \leq \Phi_{2} \leq \Phi_{1} \leq \Phi_{\max }
$$

It also follows from the last expression that the value $\Delta$ may vary from zero to $\Phi_{\max }$. In this case, $\Delta=0$ if $\Phi_{1}=\Phi_{2} \neq 0$ and $\Delta=\Phi_{\max }$ if $\Phi_{1}=\Phi_{\max }$ and $\Phi_{2}=0$.

All the above properties and relationships of the parameters $\Phi_{1}, \Phi_{2}$ and $\Delta$ could be presented in a form of a diagram shown in Fig. 2. The dashed rectangular triangle in this diagram corresponds to the region of the values of the fluxes $\Phi_{1}$ and $\Phi_{2}$ that satisfy condition (6). This triangle hypotenuse defines the region of electron fluxes, for which $\Phi_{1}=\Phi_{2}$ and $\Delta=0$. In this case, the lower vertex of triangle with coordinates $\Phi_{1}=\Phi_{2}=0$ should be removed from this diagonal, which corresponds to the lack of the object on the probing electron path (i.e. both areas are the "holes"). Vertical sections in the dashed triangle region determine the ranges of possible variation of the flux $\Phi_{1}$ and parameter $\Delta$ for the image with fixed $\Phi_{2}$ value. For a certain local area with $\Phi_{2}=0$, the electron flux $\Phi_{1}$ from other local area and the parameter $\Delta$ may vary within an entire specified interval from 0 to $\Phi_{\max }$ (Fig. 2). At the same time for the flux value $\Phi_{2}=0,5 \Phi_{\max }$ the value $\Phi_{1}$ may vary from $0,5 \Phi_{\max }$ to $\Phi_{\max }$ only, while the parameter $\Delta-$ from 0 to $0,5 \Phi_{\max }$ only (Fig. 2). The point in the diagram with coordinates $\Phi_{1}=\Phi_{2}=\Phi_{\max }$ corresponds to the case of a homogeneous sample with the boundary parameters for the quantitative electron microscopy. In general, the upper limit of the interval of parameter $\Delta$ variation depends on the flux value $\Phi_{2}$ and is equal to $\Delta_{\max }=\Phi_{\max }-\Phi_{2}$

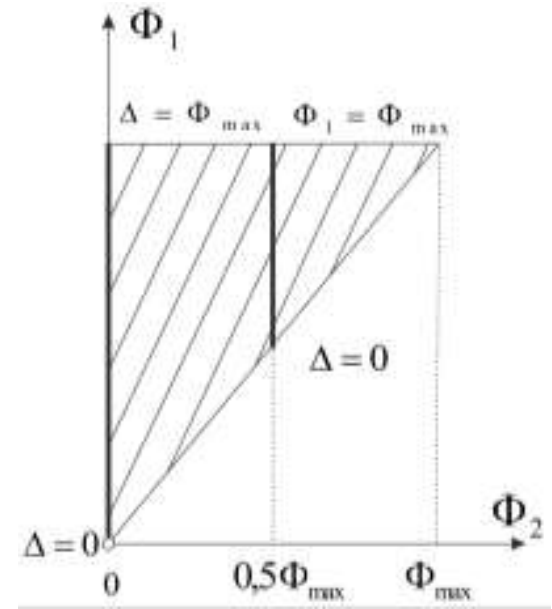

Fig. 2 - Relationship between the parameters $\Phi_{1}, \Phi_{2}$ and $\Delta$

Formulae (3) and (5) express the value $\Delta$ in the electron beam flux units. Let us analyze whether it is possible to modify them in such a way to obtain the contrast values in more convenient relative units as in (2). To do this, expression (5) must be "normalized" by such a normalizing factor a that allows the contrast between the two local areas of the EM image to be determined as $K=a \Delta$ in relative units. Obviously, the dimensionality of such a normalizing factor must be reciprocal to that of the electron flux $\Phi$. Then as the normalizing factor $\alpha$ one may suggest different values reciprocal to $\Phi$, i.e. $\Phi_{0}, \Phi_{1}$ or $\Phi_{2},\left(\Phi_{1}+\Phi_{2}\right), 0,5\left(\Phi_{1}+\Phi_{2}\right)$ and $\bar{\Phi}$, where $\bar{\Phi}$ is the value of the flux of electron waves scattered beyond the aperture diaphragm averaged over all the local areas of the object. The use of each of suggested normalizing factors has its own positive and negative consequences, main of them being presented in Table 1.

It follows from the analysis of regularities in Table 1 that the most optimal, in our opinion, is the use of relation $K=a \Delta$ with $a=1 / \Phi_{1}$ for the EM contrast. Then

$$
K=\left(\Phi_{1}-\Phi_{2}\right) / \Phi_{1}=1-\Phi_{2} / \Phi_{1}=\Delta / \Phi_{1}
$$

\begin{tabular}{|c|c|c|}
\hline Normalizing factor $\alpha$ & Positive consequences & Negative consequences \\
\hline $1 / \Phi_{0}$ & $\begin{array}{l}\text { Linear dependence between } \\
\text { the intensity variations and } \mathrm{K} \text {. }\end{array}$ & $\begin{array}{l}\text { Significant technical difficulties in } \\
\text { measuring the } I_{0} \text { value. Both the normalizing } \\
\text { factor and the contrast value are very low. }\end{array}$ \\
\hline $1 / \Phi_{1}$ or $1 / \Phi_{2}$ & $\begin{array}{l}\text { Linear dependence between } \\
\text { the intensity variations and } \mathrm{K} \text {. } \\
\text { The contrast varies from } 0 \text { to } 1 .\end{array}$ & $\begin{array}{l}\text { The value of the contrast depends on the } \\
\text { value } \Phi_{1}\left(\text { or } \Phi_{2}\right) \text {. }\end{array}$ \\
\hline $\begin{array}{l}1 /\left(\Phi_{1}+\Phi_{2}\right) \text { or } \\
1 /\left[0,5\left(\Phi_{1}+\Phi_{2}\right)\right]\end{array}$ & $\begin{array}{l}\text { The contrast varies from } 0 \text { to } 1 \\
\text { (or from } 0 \text { to } 2 \text { ). }\end{array}$ & $\begin{array}{l}\text { Non-linear dependence between the flux } \\
\text { variations and } K \text {. The contrast value depends } \\
\text { on the values } \Phi_{1} \text { (or } \Phi_{2} \text { ). }\end{array}$ \\
\hline $1 /(\bar{\Phi})$ & $\begin{array}{l}\text { Linear dependence between } \\
\text { intensity variations and K. The } \\
\text { contrast value does not depend on } \\
\text { the values } \Phi_{1} \text { and } \Phi_{2} \text {. }\end{array}$ & $\begin{array}{l}\text { The contrast value depends on } \bar{\Phi} \text {. In order } \\
\text { to determine } \bar{\Phi} \text {, large-scale measurements are } \\
\text { necessary. }\end{array}$ \\
\hline
\end{tabular}

Table 1 - Positive and negative consequences of using different "normalizing" factors in expression (5) for the EM contrast 
In (7), for explicitness, the denominator comprises the flux value $\Phi_{1}$. If one replaces $\Phi_{1}$ by $\Phi_{2}$, nothing changes, in principle.

Determination of the contrast (7) ensures the following important conditions: i) linear dependence of the contrast value between the elements of the image for two local areas of the object on the difference of the total fluxes $\Phi$ of electron beams formed by these elements; ii) contrast variations are registered in the interval from 0 до 1 relative unit; iii) the contrast value can be determined both through the variation $\Delta$ of the fluxes $\Phi_{1}, \Phi_{2}$ and via their ratio $\Phi_{2} / \Phi_{1}$ (see relation (7)). The negative consequences shown in Table 1 have no fundamental importance. This is due to the fact that when analyzing the contrast we use information from one EM image with a constant flux $I_{0}$ only. Using this image, we find experimentally the values $\Phi_{1}$ and $\Phi_{2}$ for further calculations. Selection of the larger value from the two determined ones and assignment of notation $\Phi_{1}$ for it have no fundamental difficulties. Such larger by its value flux is then used by us as the "normalizing" factor as well.

Note that determination of the contrast value via expression

$$
K=\Delta / \bar{\Phi} .
$$

is identical to that in relation (7), however, in this case the contrast values are normalized not to the intensity $\Phi_{1}$, but to the average intensity of the electron flux $\bar{\Phi}$ over the entire plane of the image formation. Thus, the practical application of relation (8) requires much more large-scale measurements and mathematical calculations to determine the value $\bar{\Phi}$, not giving any preferences.

In relation (7), the flux value $\Phi_{i}$ for a certain local area of the sample is determined by the total contribution of all its structural parameters, i.e. the chemical composition, the atomic structure, the geometrical thickness, the presence of nanopores etc. Therefore, the determined contrast value $K$ will reflect by all the structural parameters the integral difference of the two areas under analysis. It is not a simple experimental task to find the contribution to the contrast of one of the above parameters. In our opinion, it must include the X-ray microanalysis of the differences in the chemical composition of these areas with nanometer locality; the micro- and nanodiffractional investigations of their atomic structure with the registration of the relevant diffractograms; the measurements of the geometrical thicknesses of these areas, e.g. by the force microscopy methods. Today such studies are being carried out by us for the amorphous films of some arsenic and germanium chalcogenides.

\section{CONCLUSIONS}

To determine quantitatively the amplitude contrast of the electron-microscopic images it seems expedient to apply a strict approach similar to that used in optics. In accordance with such approach, it has been suggested to calculate the amplitude (absorption) contrast in the electron-microscopy images of the amorphous objects with different types of heterogeneities of the atomic and continual structure as $K=\left(\Phi_{1}-\Phi_{2}\right) / \Phi_{1}$, where $\Phi_{1}$ and $\Phi_{2}$ are the total fluxes of electrons scattered beyond the aperture diaphragm by the two analyzed local areas of the object under study. The important properties of the contrast determined in such a way are its linear dependence on the difference of the fluxes of the electron beams forming the image, convenient range of variation from 0 to 1 relative unit, independence on the probing beam intensity, possibility of direct calculations of the contrast value based on the results of the micro- and nano-diffraction studies.

\title{
Контраст електронномікроскопічних зображень аморфних об’ектів
}

\section{О.Я. Сватюк}

\author{
Ужгородський національний університет, вул. Підгірна, 46, 88000 Ужгород, Украӥна
}

\begin{abstract}
Запропоновано визначення контрасту електронномікроскопічних зображень як функції електронних потоків розсіяних в межах апертурної діафрагми різними локальними ділянками обєєту. Обгрунтовано використання такого підходу для кількісного визначення величини амплітудного (абсорбційного) контрасту на зображеннях аморфних об'єктів з різними типами гетерогенності атомної та континуальної структури. Важливою особливістю визначеного контрасту є лінійна залежність від різниці електронних потоків, які формують зображення, та зручна область змін величини контрасту від 0 до 1 відносних одиниць.
\end{abstract}

Ключові слова: Електронна мікроскопія, Дифракція електронів, Амплітудний контраст, Аморфні матеріали, Мікроструктура. 


\title{
Контраст электронномикроскопических изображений аморфных объектов
}

\author{
А.Я. Сватюк
}

Ужгородский национальньй университет, ул. Пидгирна, 46, 88000 Ужгород, Украина

Предложено определение контраста электронномикроскопических изображений как фрункции электронных потоков, рассеянных в пределах апертурной диафрагмы разными локальными участками объекта. Обосновано использование такого подхода для количественного определения величины амплитудного (абсорбционного) контраста на изображениях аморфных объектов с разными типами гетерогенности атомной и континуальной структуры. Важной особенностью определенного контраста есть линейная зависимость от разности электронных потоков, которые фрормируют изображение, и удобный диапазон изменений контраста от 0 до 1 относительных единиц.

Ключевые слова: Электронная микроскопия, Дифракция электронов, Амплитудный контраст, Аморфные материалы, Микроструктура.

\section{REFERENCES}

1. P.J. Goodhew, F.J. Humphreys, R. Beanland, Electron microscopy and analysis (New York: Taylor \& Francis: 2001).

2. D.B. Williams, C.B. Carter, Transmission Electron Microscopy: A Textbook for Materials Science (New York: Springer: 2009).

3. B. Fultz, J. Howe, Transmission ElectronMicroscopy and Diffractometry of Materials (New York: Springer: 2007).

4. L. Reimer, H. Kohl, Transmission Electron Microscopy: Physics of Image Formation (New York: Springer: 2008).

5. R. Egerton, Physical principles of electron microscopy (New York: Springer: 2005).

6. P. Hawkes, The beginnings of Electron Microscopy (Orlando: Academic Press: 1985).

7. L.E. Ross, M. Dykstra, Biological Electron Microscopy: Theory, techniques and troubleshooting (New York: Springer: 2003)

8. Yi Liu, D.J. Sellmyer, D. Shindo, Handbook of Advanced Magnetic Materials. Vol 1. Nanostructural Effects (New
York: Springer: 2006)

9. A.G. Dirks, H.J. Leamy, Thin Solid Films 47 No 1, 219 (1977).

10. R.J. Martín-Palma, J.V. Ryan, C.G. Pantano, J. Appl. Phys. 101, 083513 (2007).

11. A.G. Bagmut, V.M. Kosevich, G.P. Nikolaichuk, Functional Mater. 7, 836 (2000).

12. D.B. Williams, C.B. Carter, Transmission Electron Microscopy (New York: Plenum Press: 1996).

13. M. Born, E. Wolf, Principles of Optics (4th.ed.) (Oxford: Pergamon Press: 1970).

14. G.S. McDarrah, The photography encyclopedia (New York: Schirmer: 1999).

15. M.Y. Bobyk, V.P. Ivanytskiy, V.S. Kovtunenko, O.Y. Svatyuk, J. Nano- Electron. Phys. 4 No 2, 02041 (2012).

16. Y. Hirotsu, I. Manabu, O. Tadakatsu, H. Takeshi, S. Masaaki, J. Electron. Microscopy 50 No 6, 435 (2001). 